\title{
O Conteúdo da Intervenção Profissional em Educação Física: O ponto de vista de docentes de um curso de formação profissional
}

\author{
Paula Evelise Fávaro" \\ Glauce Yara do Nascimento** \\ Jeane Barcelos Soriano***
}

\begin{abstract}
Resumo: Tivemos como objetivo desse estudo verificar o ponto de vista dos docentes de um curso de formação profissional sobre: (a) como se caracteriza a intervenção profissional em Educação Física: (b) que elementos a compõe; (c) e como esses elementos devem ser articulados pelos profissionais de Educação Física durante o processo de tomada de decisão. Para isso, utilizamos a abordagem qualitativa de pesquisa e a partir de dados obtidos em entrevistas semi-estruturadas, empregamos análise de conteúdo com categorias estabelecidas à priori, sobre (a) mercado de trabalho, (b) conhecimentos, habilidades, atitudes a serem desenvolvidas durante a graduação; (c) sistema de avaliação; (d) visão da graduação em Educação Física. Pôdese considerar que, apesar do grupo estudado expressar algumas preocupações importantes com relação à valorização dos conhecimentos oriundos das disciplinas-mãe, habilidades motoras e da pesquisa científica, os pontos de vista manifestados nesse estudo não permitiram definir claramente, nem caracterizar os elementos que devem compor a intervenção profissional em Educação Física.

Palavras-chave: Capacitação Profissional. Ensino. Conhecimento. Educação Física.
\end{abstract}

\section{Introdução}

Atualmente as mudanças na legislação, economia e no mercado de trabalho apontam para uma série de competências que são cada vez mais exigidas dos profissionais. Muitas vezes, no intuito

Grupo de Estudos sobre a Intervenção do Profissional de Educação Física (GEIPEF).Centro de Educação Física e Desportos. Universidade Estadual de Londrina, PR. E-mail: paulaegiulia@yahoo.com.br e/ou pefavaro@ hotmail.com

E-mail: glauceyara @ pop.com.br

E-mail: soriano@sercomtel.com.br e/ou jeane@uel.br

Movimento, Porto Alegre, v.12, n. 02, p. 199-221, maio/agosto de 2006. 
de acompanhar essas mudanças, várias Instituições de Ensino Superior vêm atualizando seus currículos de Educação Física, sempre apontando para o atendimento necessário às novas perspectivas de ampliação mercado de trabalho, anteriormente restrito ao ambiente escolar. No entanto, o que se tem constatado são mudanças curriculares superficiais, com a inserção de umas poucas disciplinas com nomes de locais de atuação, ou conservadoras, com ênfase em modalidades esportivas e/ou aumento de carga horária de áreas de conhecimento mais tradicionais (VERENGUER, 1996).

Além disso, sabe-se que a maioria dos cursos ainda se organizava em torno do que conhecemos como Licenciatura Generalista, ainda que desde a Resolução 03/87 (BRASIL, 1987) se vislumbrasse a formação, essencialmente, de bacharéis, as instituições acabaram por meio dessa mesma resolução abrigando a possibilidade de formação do "licenciado" com perspectiva e possibilidades "ampliadas", com a prerrogativa de que, assim, se estaria assegurando a possibilidade de atuação em qualquer campo de atuação. (BRASIL, 2005; VERENGUER, 1996).

A decorrência mais forte dessa interpretação é, reconhecidamente, a falta de definição quanto ao tipo e especificidade do conjunto de conhecimentos e habilidades que deveriam compor uma formação, que venha ao encontro de um campo profissional diversificado e em expansão (SORIANO, 2003; VERENGUER, 2003), com várias possibilidades de interação multiprofissional (NASCIMENTO, 2004), gerando junto às repostas profissionais um paradoxo diante daquilo que a formação deveria proporcionar, qual seja a ausência de elementos que deveriam estar na base dos processos de tomar decisões nas intervenções profissionais.

Em outras palavras, ao mesmo tempo em que se pretendia formar um licenciado para atuar na escola, também se tinha o intuito de formar um profissional capaz de atender as novas oportunidades de atuação fora dela, na tentativa de não limitar as possibilidades de atuação do egresso em Educação Física. Dessa

Movimento, Porto Alegre, v.12, n. 02, p. 199-221, maio/agosto de 2006. 
forma, as propostas curriculares foram insufladas de disciplinas díspares e com pouca profundidade, originando uma "tradição" na área de se defender os aspectos imediatistas de mercado de trabalho e, também, de atrelar ingenuamente atributos "didático-pedagógicos" à intervenções em espaços não escolares (REIS, 2002). Portanto, uma das implicações mais sérias seria que:

\section{[...] sem o reconhecimento das diferenças en- tre o mercado de trabalho na escola e fora dela, torna-se mais difícil à tentativa de avaliar as particularidades e conseqüências da interven- ção, quando nem ao menos se tem o domínio dos conhecimentos que devem ser utilizados em cada um deles (NASCIMENTO, 2004, p. 13).}

No entanto, a partir da publicação das Resoluções CNE/CP 01 e 02/2002, consolida-se a necessidade de uma re-leitura do entendimento de Licenciatura de maneira geral, e na Educação Física particularmente. Como decorrência da implementação das resoluções, fez-se clara a necessidade de repensar não apenas a mudança de nome, mas também de objetivos e perfis profissiográficos (Resolução $\mathrm{n}^{\circ} .07 / 2004$ ). Tudo isso guarda em si uma séria implicação na conformação dos conhecimentos e habilidades profissionais que fazem parte de um curso. Além da perspectiva que o próprio docente tem quando da seleção de conteúdo e organização metodológica de sua disciplina numa estrutura curricular.

Assim, nota-se que docentes do ensino superior ainda possuem pouca clareza acerca de elementos essenciais e diferenciadores entre preparação pautada para intervenção no ensino dentro da escola e no ensino fora da escola. Um dos motivos para tal confusão talvez esteja no fato de encararem de modo romântico o mercado de trabalho em Educação Física, transmitindo como honrosa à atuação dentro da escola e como desafiadora a atuação fora dela.

Diante disso, acreditamos que devemos nos preocupar com os futuros profissionais que se formam nas escolas de Educação

Movimento, Porto Alegre, v.12, n. 02, p. 199-221, maio/agosto de 2006. 
Física, porque a formação profissional interfere e influencia no decorrer do desenvolvimento do profissional, bem como, imprimem no modo de ser, valores, costumes, justificativas de como vêem sua intervenção.

Considerando que a maioria dos cursos de Licenciatura sempre valorizaram a execução de movimentos com um fim em si mesmo, desse modo Bok (1988) acrescenta que os docentes não podem se contentar em ensinar aos estudantes a se lembrar de um corpo fixo de conhecimentos; em vez disso, devem ajudá-los a dominar técnicas de resolver problemas e hábitos de aprendizado contínuo.

Sendo assim, para Tani (1996) a implementação de uma grade curricular com ou sem vivências práticas depende de uma definição nítida do perfil profissional do graduando que se quer formar, e este perfil deve estar ligado às necessidades sociais e as características mutáveis do mercado de trabalho. O modelo ideal para o qual a maioria das profissões aspira, pode ser descrito, mas raramente aplicado e está ele mesmo em constante mudança. Para nós compreendermos algumas tendências, temos que analisar mais de perto o mercado de trabalho dos profissionais e a natureza inconstante do cliente ou dos sistemas de clientes (SCHEIN, KOMMERS, 1972; BOK, 1988).

Para Bok (1988) o progresso do ensino profissional ocorre devido às pressões da sociedade, dos estudantes, da comunidade acadêmica com seus hábitos e atitudes enraizadas dentro da Universidade, e da própria profissão que os lembra a todo instante de preparar pessoas competentes para o exercício profissional. $\mathrm{O}$ autor ainda argumenta que para um ambiente de melhor aprendizado as Universidades devem evitar apenas concentrar esforços para adicionar novos cursos e reorganizar programas, porque assim acabase enfatizando mais o que os professores ensinam e ignorando como os alunos aprendem. Portanto, é preciso: (a) incentivar a pesquisa, já que as Universidades existem por causa dela, (b) in-

Movimento, Porto Alegre, v.12, n. 02, p. 199-221, maio/agosto de 2006. 
centivar a avaliação sistemática e minuciosa de cursos que ajudarão os docentes a descobrirem áreas nas quais o ensino e as matérias precisam de aperfeiçoamento, (c) proporcionar a esses docentes que desejam melhorar suas aulas, novos métodos de instrução (multimeios), (d) dar assistência a jovens docentes e a estudantes graduados para aprimorarem suas técnicas de ensino. Dessa forma, os docentes se sentirão motivados a melhorar a qualidade do ensino, porém, precisam trabalhar em colaboração.

Kourganoff (1990) revela que os docentes devem tomar cuidado com a incessante valorização da pesquisa científica em detrimento a desvalorização do ensino. $\mathrm{O}$ autor aponta a existência de dois tipos de basicamente dois tipos de carreiras acadêmicas, ou seja, de atividades profissionais que caracterizam os professores universitários: o professor pesquisador que possui interesse e dedicação para a pesquisa e, o professor "de ensino", ou seja, o professor propriamente dito. É importante ressaltar que ambos profissionais tem seu valor, o problema é quando dentro de um sistema educacional não existe incentivo que permite a dedicação a pesquisa, nem a valorização daqueles profissionais comprometidos com o ensino.

Hoje o que as Universidades mais precisam é de um esforço determinado para avaliar novas iniciativas e integrar as bem sucedidas no corpo principal do currículo onde elas podem ter maior permanência e atingir maior número de estudantes. No entanto, os que oferecem maiores resistências para que as mudanças necessárias ocorram são os próprios membros do corpo docente, onde para eles se alguma parte tiver que ceder que seja o ensino, pois consideram a pesquisa mais importante (BOK, 1988). Até mesmo porque são julgados e promovidos apenas em função de sua atividade de pesquisa, ficando os estudantes em segundo plano (KOURGANOFF, 1990).

O objetivo desse estudo foi verificar o ponto de vista dos docentes de preparação profissional em Educação Física do CEFD-

Movimento, Porto Alegre, v.12, n. 01, p. 153-171, janeiro/abril de 2006. 
UEL levando-se em conta os seguintes aspectos: (a) como se caracteriza a intervenção profissional em Educação Física; (b) que elementos a compõe; (c) e como esses elementos devem ser articulados pelos profissionais de Educação Física durante o processo de tomada de decisão. Para assim poder ter uma maior compreensão sobre as ocorrências, procedimentos e referências adotadas no processo educativo da preparação profissional na área.

Dessa maneira, é nossa pretensão apresentar os resultados de nossa reflexão, após um trabalho de campo, na direção de apontar melhores encaminhamentos para formação profissional em Educação Física, bem como mapear a maneira como os docentes vêem as ações profissionais, buscando assim propiciar uma transição significativa para a formação profissional dos futuros egressos.

\section{Encaminhamento metodológico}

Neste estudo utilizamos a abordagem qualitativa, seguindo as diretrizes do estudo de caso de acordo com Triviños (1987), Laville e Dionne (1999), Richardson (1999), para levantar dados, preservando o caráter unitário do "objeto" a ser estudado, e tentar abranger as características mais importantes do tema que se está perseguindo. O tipo de estudo se caracterizou como exploratório, por não haver manipulação de variáveis (TRIVIÑOS, 1987).

A fim de atingir os objetivos propostos nesse estudo, recorreu-se à elaboração de um roteiro de questões, na tentativa de responder às inquietações surgidas do envolvimento com estudos relacionados aos elementos que devem compor a ação profissional dos professores universitários de Educação Física, e como esses elementos são caracterizados. Nessa pesquisa, optou-se pela utilização da entrevista semi-estruturada junto aos docentes do CEFD-UEL. Salientamos que esse tipo de entrevista é utilizado para estudar os processos e produtos nos quais o investigador está mais diretamente interessado (TRIVIÑNOS, 1987).

Movimento, Porto Alegre, v.12, n. 02, p. 199-221, maio/agosto de 2006. 
Baseando-se na literatura e seguindo as orientações de Trylinski (1974) elaboramos um roteiro de entrevista, que corresponde à entrevista semi-estruturada de forma individual, para que pudéssemos averiguar que elementos devem compor a ação profissional de Educação Física e como esses elementos se caracterizam, segundo o ponto de vista dos docentes do curso de preparação profissional.

Utilizamos para registrar os depoimentos dos docentes gravações em fita K-7, as quais foram transcritas na íntegra, totalizando 108 páginas para análise.

Foi realizado um convite a todos os docentes do CEFD-UEL por meio de uma carta. Aceitaram participar do estudo 15 docentes. No entanto, apenas 13 depoimentos foram aproveitados devido aos problemas com os recursos de coleta de dados, como a má qualidade do material utilizado e do baixo volume, impossibilitando a audição daquilo que foi registrado.

As respostas dos docentes foram analisadas pela aplicação da técnica de análise de conteúdo, descrita por Bardin (1979). As categorias de análise foram estabelecidas a priori, ou seja, procuramos formular as perguntas da entrevista e a análise baseando-nos em temas estabelecidos de acordo com o referencial teórico. Uma das limitações das categorias à priori é passar desapercebidos pontos, pontuações, observações significantes obtidas da fala do entrevistado, dentro dessa limitação abre-se espaço para colocar impressões a partir do olhar da totalidade das falas dos participantes.

As categorias estabelecidas neste estudo foram os seguintes: (1) Mercado de trabalho; (2) Conhecimentos, habilidades, atitudes a serem desenvolvidas durante a graduação; (3) Sistema de avaliação; (4) Visão da graduação em Educação Física.

Movimento, Porto Alegre, v.12, n. 02, p. 199-221, maio/agosto de 2006. 


\section{Análise e discussão}

\subsection{Categoria 1: Mercado de trabalho}

As possibilidades de atuação mencionadas pelos docentes, referente ao mercado de trabalho, são as seguintes: onze dos docentes citaram a academia, oito entrevistados citaram os clubes e sete profissionais citaram personal trainer. Apenas um docente considerou como possibilidade de atuação a assessoria de imprensa, a publicação de livros, a construção de equipamentos, a ginástica laboral, atuação em instâncias térmicas, organizações assistencialistas, asilos e prefeitura. E ainda três docentes citaram hospitais, hotéis e esporte e outros dois citaram o treinamento esportivo e a saúde.

Quanto aos conteúdos de cada disciplina, relacionado com o mercado de trabalho, cinco docentes incluem em seus conteúdos a técnica do esporte, ou seja, saber a técnica correta relacionada às modalidades esportivas: "[...] o conteúdo é fundamentado na questão técnica do desporto[...]”, "[...] possibilitar a atuação no mercado de trabalho voltado principalmente à formação, iniciação da formação do atleta e também para o treinamento[...]"

As respostas dos entrevistados apontam que de certa forma acompanham com pouca clareza as mudanças do mercado de trabalho, sem visualizar as novas definições do papel profissional e sua responsabilidade com os usuários, ou seja, o que a sociedade necessita do profissional de Educação Física (SCHEIN; KOMMERS, 1972). Conseqüentemente, não enxergam com nitidez quais as possibilidades de atuação do profissional de Educação Física, dessa forma, os conteúdos de suas disciplinas se restringem às técnicas atreladas ao esporte, transmitidos através de seqüências pedagógicas, resumindo-se à simples transmissão do conhecimento acumulado pelo docente durante anos, apoiada em experiência, intuição e senso comum (TANI, 1996). Essa circunstância faz com que os graduandos tenham uma vaga idéia de como

Movimento, Porto Alegre, v.12, n. 02, p. 199-221, maio/agosto de 2006. 
suas instruções influenciarão de fato na sociedade (SCHEIN; KOMMERS, 1972).

Isso contribui para a visão da qual professor de Educação Física seja reconhecido como um eterno repetidor de procedimentos de duvidosa fundamentação teórica, sem conhecer sua real função dentro do processo educacional, e seu potencial de contribuição para o desenvolvimento de seus alunos, como mencionado por Teixeira (1993).

As principais situações-problema que os profissionais enfrentam no mercado de trabalho, de acordo com cinco dos docentes, são problemas referentes à especificidade da Educação Física, decorrente de confusões conceituais, forma de tratamento da área e a diversificação de métodos de investigação: "[...] nós mesmos não temos clareza em relação ao objeto de estudo."

O não conhecimento da especificidade da Educação Física, de acordo com os entrevistados, acarretam outras situações como a falta de credibilidade do profissional de Educação Física, levando ao não reconhecimento do profissional pela sociedade, como foi relatado por cinco dos entrevistados. Além disso, existem outras situações apontadas como a carência de definição do que o profissional de Educação Física faria no mercado de trabalho, assim como a remuneração sobre os serviços prestados: "[...] aí a questão salarial reflete em muitos outros fatores: você não tem condições de se reciclar, adquirir revistas, fazer cursos."

Os docentes também apontaram outros fatores relacionados à identidade e ao status profissional, como a ausência de crédito pessoal do profissional de Educação Física, individualismo e falta de profissionalismo. Podemos dizer que essa situação é decorrente da ausência de um objeto de estudo definido, e que acaba deixando os profissionais dependentes de outras áreas, especialmente no trabalho em equipes multiprofissionais, bem como habituados a conceitos tradicionais (GHILARDI, 1998). "Nós somos os primeiros a não acreditar em nós mesmos". "[...] A sociedade

Movimento, Porto Alegre, v.12, n. 02, p. 199-221, maio/agosto de 2006. 
ainda não aprendeu a dar o valor devido aos nossos profissionais."

Os entrevistados relataram a distância entre o conteúdo ensinado à realidade profissional, bem como questões acerca da falta de visibilidade do profissional quanto ao mercado de trabalho, como a carência de inovação nos serviços prestados e a falta de visão de marketing. "Hoje infelizmente com o currículo que nós temos, com o tipo de conteúdo que nós passamos o profissional não consegue aplicar na prática o que aprendeu."

Com relação as principais estratégias adotadas para o ensino, concernentes às situações-problema enfrentadas no mercado de trabalho, nove docentes se referiram às discussões e debates: (a) de textos ou artigos relacionados ou não com a disciplina ministrada; (b) recorte de jornais e revistas; (c) multi-meios (filmes, slides, transparências) (d) relato de experiências proporcionado por profissionais convidados. Dois docentes defenderam os estágios como formas de aprendizado e formação do profissional. Outros dois docentes lançam mão da estratégia de transmitir o conhecimento generalizado, deixando para o aluno a responsabilidade de síntese, correlação e utilização desses conhecimentos: "Dentro da disciplina conhecimentos generalizado [...] os alunos que vão ter que pensar naquilo que puderem relacionar com a modalidade." - "Não posso ficar vendo aquilo que cada um quer dentro de uma aula".

Quanto aos procedimentos adotados para aumentar a eficácia do processo ensino-aprendizagem no ensino superior, quatro docentes consideraram que deveriam ser feitos através de debates sobre textos e quatro docentes por meio de estágios: (a) trazer o que está acontecendo no mercado de trabalho para serem discutidos na sala de aula; (b) problematização; (c) aplicar o que foi ensinado a uma situação real logo após a aula teórica e, (d) participação em projetos de extensão.

Um docente considerou como procedimento importante para o processo ensino-aprendizagem, o comprometimento de professores e alunos com suas tarefas; o aluno estar em contato com as

Movimento, Porto Alegre, v.12, n. 02, p. 199-221, maio/agosto de 2006. 
áreas de atuação (realizar visitas em escolas públicas, etc) e também despertar interesse pela de pesquisa, ou seja, aplicar estratégias que sejam mais significativas para o aluno, trazendo experiências deste para sala de aula.

Parece contraditório que alguns docentes utilizam-se de situações do mercado de trabalho como estratégia para aumentar a eficácia no processo ensino-aprendizagem, no entanto, pouca clareza possuem sobre as subjetividades do mercado de trabalho.

Fica claro que julgam necessário chegar a um consenso sobre qual a especificidade e forma de tratamento da área. Nota-se dessa forma, que os docentes possuem um grande desejo de reforma e conforme Bok (1988), mudanças bem sucedidas ocorrem através de novas idéias e percepções inéditas constantemente adicionadas aos cursos tradicionais e a contínua introdução desses assuntos aos conteúdos a serem transmitidos pelos docentes. No entanto, observa-se que os professores estão poucos suscetíveis a perceber as mudanças que ocorrem no mercado de trabalho, aumentando a resistência a reformas curriculares.

Percebe-se que o tipo de estratégia considerada adequada para a atuação no mercado de trabalho, como a discussão e debates de textos e a inclusão de estágios pode aumentar a eficácia do processo ensino aprendizagem. Para Bok (1988) a discussão de textos leva os estudantes a analisar, dar opiniões, sendo assim, pensar sobre os problemas característicos da profissão. Os estágios oferecem uma forma de treinar estudantes habilidades práticas, ao mesmo tempo em que proporciona importantes serviços a sociedade.

Entretanto, os docentes encontram dificuldades relacionadas à indisponibilidade de horário e até mesmo falta de vontade dos alunos. Por outro lado, o docente deve refletir sobre seus métodos de ensino, ou seja, avaliar e reavaliar constantemente suas ações a fim de dirimir esses problemas de motivação.

Movimento, Porto Alegre, v.12, n. 02, p. 199-221, maio/agosto de 2006. 


\subsection{Categoria 2: Conhecimentos, habilidades e atitudes a serem desenvolvidos durante a graduação}

Os conhecimentos que os profissionais deveriam possuir para iniciar a sua atuação são conhecimentos relacionados às áreas mãe como sociologia, filosofia, biologia, psicologia e pedagogia que foram citados por oito dos docentes. Os demais conhecimentos citados por apenas um docente seriam conhecimentos sobre o que a clientela necessita, conhecimento da área que vai atuar, saber planejar aula e saber ensinar a habilidade específica do desporto.

Em relação como se caracteriza o conhecimento profissional há um consenso de sete dos entrevistados como sendo teórico e prático, mas, entre estes, a prática se diferencia em técnicas próprias das modalidades esportivas:

\section{[...] o teórico fala coisas que como ele não vivenciou na prática são absurdas, então acre- dito no professor que tenha a noção prática [...] \\ [...] deve ter fundamentação teórica e a funda- mentação prática, não no que se refere à habi- lidade de execução e perfeição, mas, habilida- de mínima de execução em determinado gesto que futuramente talvez seja necessário[...]}

Apenas para um docente o conhecimento profissional se caracteriza pela vivência da prática. Outros quatro entrevistados indicaram que o conhecimento profissional se caracteriza no campo do movimentar-se, ou seja, motricidade humana.

Em um dos depoimentos foi apontada a relevância do conhecimento teórico e aplicação da teoria, no entanto, não conseguimos compreender que tipo de relação estaria por traz dessa aplicação da teoria, se refere a conhecimento ou a execução de determinado movimento. Um docente não soube caracterizar, e outro não caracterizou por entender que primeiro é preciso reconhecer o papel do professor de Educação Física na escola, para depois saber o que faz fora dela.

Movimento, Porto Alegre, v.12, n. 02, p. 199-221, maio/agosto de 2006. 


\begin{abstract}
[...] nós não temos claro o que a disciplina Educação Física faz no segmento escolar [...] uma área se torna forte no dia em que a correlata dela no segmento escolarização seja no ensino fundamental, médio ou a universidade está claramente definido.
\end{abstract}

O tipo de conhecimentos que os docentes consideram como requisito para preparação profissional são teóricos: relacionadas às áreas mães e práticos relacionados a habilidades motoras. Dessa forma Teixeira (1993) argumenta que se deve preocupar em beneficiar os graduandos com habilidades essenciais ao exercício profissional, em vez de habilidades motoras relacionadas ao esporte, logo, ensiná-los a analisar respostas de seus alunos para adequar diversas variáveis de ensino é o que se esperaria dos responsáveis pela formação dos profissionais na área.

Nesse caso concordamos com Ghilardi (1998) quando afirma que os cursos de licenciatura sempre valorizaram a execução de movimentos com um fim em si mesmo. O produto que se busca é a formação de profissionais e não de atletas e a atividade de ambos é eminentemente intelectual e não física. De forma semelhante Tani (1996) sugere que se deva privilegiar a oportunidade para o graduando desenvolver a capacidade diagnóstica, capacidade de observação para conhecer o que o aluno necessita aprender.

Com relação ao processo ensino-aprendizagem, nove entrevistados consideraram importantes as situações referentes à desvalorização do profissional de Educação Física no mercado de trabalho, da qual são decorrentes das seguintes situações: (a)falta de responsabilidade, seriedade e comprometimento, inclusive de graduandos que se aventuram precocemente no mercado de trabalho; (b) não sabem como lidar com os alunos e/ou clientes; (c) não diferenciam conceitos de senso comum de conceitos científicos, e (d) não sabem inovar em seus serviços.

Movimento, Porto Alegre, v.12, n. 02, p. 199-221, maio/agosto de 2006. 
[...] muito acadêmico dando aula, primeiro ano trabalhando como personal! [...] isso faz com que tenha um baixo rendimento profissional que acaba refletindo na categoria inteira.

[...] no mercado que nós temos aí existem muitos mitos, o profissional não sabe definições mais simples de bem estar, a falta de diferenciação entre o que venha ser escola e o que venha ser lazer.

Quatro entrevistados não souberam responder a pergunta fugindo do tema demonstrando mais uma vez que se apropriam do tema mercado de trabalho como conteúdo para ministrar suas disciplinas, sem ao menos identificar quais são os principais problemas enfrentados. "não faço discussões porque a matéria tem carga horária reduzida, por isso não trabalho com a prática, então não tem como fazer discussões."

Quanto às habilidades, oito docentes declaram que os graduandos deveriam dominar e saber recrutar conhecimentos necessários para resolver determinada situação da área em que vai atuar. Nesse caso, disseram que as habilidades que os egressos deveriam apresentar são "saber executar e demonstrar" o movimento a ser ensinado. O restante das respostas representada pelos outros docentes foram as mais variadas como: fazer diagnóstico através de entrevista e observação das necessidades do local (sociedade) onde irá intervir. Além disso, comunicar-se com facilidade, saber passar segurança para o cliente e adequar a fala para cada faixa etária que irá atuar.

Observa-se que a habilidade necessária à preparação profissional é o domínio de conhecimentos necessários para resolver determinada situação da área em que vai atuar, fica evidente, que há uma fuga por parte dos docentes de quais seriam esses conhecimentos necessários, e ainda, os graduandos deveriam relacionar por si próprios com a área de atuação. Alguns justificam que esses conhecimentos são adquiridos através da habilidade do graduando

Movimento, Porto Alegre, v.12, n. 02, p. 199-221, maio/agosto de 2006. 
de saber acessar informações, seja ela através da internet ou em grupos de pesquisas. Assim, uma grande parcela valoriza o acesso a informações, estas de conteúdo científico.

Para Freidson (1998) as características de valorização do ensino de conteúdos predominantemente científico dos cursos de formação profissional revelam a importância atribuída a esse tipo de conhecimento nos dias atuais e também contribuem para a criação de diferentes tipos de docentes:

\section{Os profissionais se diferenciam por segmentos e especialidades concretas, por circunstancias diferentes de prática, por seus papéis de pro- fissional comum, professor, pesquisador e ad- ministrador, e por sua relativa proeminência como líderes culturais, políticos e intelectuais da profissão e no mundo do leigo exterior (FREIDSON, 1998, p. 71).}

Em relação as habilidades para a intervenção profissional Bok (1988) julga necessário ensinar habilidades de fazer diagnósticos e comunicação com os clientes, entretanto, estas são deixadas de lado simplesmente porque os docentes preferem não ensiná-las e sentirem-se pressionado ao fazê-las., ou seja, porque os docentes não compreendem o bastante para poder construir generalizações, induções ou estruturas conceituais dignas de serem ensinadas.

Com relação aos valores e atitudes necessárias para atuação profissional as dimensões éticas são citadas por três docentes como: (a) responsabilidade e comprometimento com o objetivo que se pretende atingir; (b) constantemente repensar se o que está sendo aplicado é realmente bom para os clientes; (c) o profissional não se oferecer para trabalhar por salário inferior. E as demais atitudes foram: honestidade, valorizar a profissão, ter consciência do que está aplicando, pontualidade, utilizar-se de uma linguagem melhor e ser um profissional sem pré-conceitos: [...] o profissional não pode ter preferência ou afinidade com uma ou outra pessoa...tem

Movimento, Porto Alegre, v.12, n. 02, p. 199-221, maio/agosto de 2006. 
que tratar as pessoas sempre com dedicação, igualdade, não interessa se é preto, se é branco, japonês, baixo ou alto.

Outros três entrevistados citaram a importância de manter-se atualizado: "[...]. estudar mais, partir em primeiro lugar para a especialização."

Essa afirmação remete novamente a valorização da pesquisa científica, atribuindo a ela o sentido de comprometimento com a profissão e também sendo motivo de status entre os docentes. Bok (1988) ressalta que a comunidade acadêmica reserva maior admiração para aqueles que demonstram excepcionais poderes de inteligência por fazerem novas descobertas, conceberem novas teorias ou contribuírem para conhecimentos de forma mais significativa. A partir dessa crença é que decorre uma tendência para valorizar mais a pesquisa do que o ensino. Mas por outro lado, o autor nos leva a refletir, que o mais importante, é estar em contato com os conhecimentos novos produzidos pela área.

\subsection{Categoria 3: Sistema de avaliação}

Como métodos de avaliação são utilizados: $30 \%$ provas teóricas, sendo objetivas e subjetivas e, provas práticas: (a) gesto técnico, citado por três docentes, (b) saber auxiliar o executante para realização de determinado movimento, citado por um entrevistado (c) estágio em determinada comunidade, citado por um entrevistado. Dois docentes utilizam o estudo de caso:"[...] crio uma situação e coloco meus alunos dentro dessa situação."

Um entrevistado utiliza a avaliação através de festival da disciplina onde é avaliada a convivência em grupo; domínio de conhecimento; avaliação contínua; avaliação global. Observa-se que a capacidade de execução de habilidades motoras é considerada como um fator indispensável, assim, os graduandos devem ser os melhores executores, ao invés de saber selecionar, identificar as dificuldades que os clientes necessitam e partir disso saber

Movimento, Porto Alegre, v.12, n. 02, p. 199-221, maio/agosto de 2006. 
intervir no contexto apresentado (TANI,1996).

Apenas quatro dos docentes não consideraram a avaliação utilizada como avaliação ideal porque argumentam que deveriam ser criados mecanismos para que o aluno fosse avaliado no seu dia-a-dia. Essa situação demonstra que nove dos docentes não utilizam a avaliação como mecanismo de analisar os problemas e as dificuldades que limitam a sua própria atuação enquanto docente (GUARNIERI, 2000).

\subsection{Categoria 4: Visão da graduação}

As dificuldades de ministrar aulas nesta instituição apontadas pela maioria dos docentes referem-se a problemas estruturais do currículo: (a) disciplina que não se articulam (b) disciplina não deveria encontrar-se no currículo, por não ser escolar e (c) carga horária reduzida para determina disciplina. As outras dificuldades apresentadas foram a falta de comunicação com outros professores que ministram a mesma disciplina; ter que ministrar outros conteúdos antes de iniciar o conteúdo da própria disciplina. Três entrevistados citaram problemas relacionados aos alunos: (a) não encontrar condições juntos aos alunos para desenvolvimento de estágios, (b) alunos inibidos, tímidos e (c) alunos que não questionam, desinteressados. [...] se o aluno não questiona o professor se acomoda. Então pra que eu vou me preocupar se ele não vai me perguntar? Então o aluno deve questionar o professor pra que o professor se atualize [...]

Quando os docentes apontam problemas referentes ao comportamento dos alunos, deve-se analisar o que pode estar por trás deste tipo de comportamento, pois isto pode refletir a utilização de estratégias e métodos de ensino ultrapassados ou conservadores.

$$
\begin{aligned}
& \text { A aptidão para receber um ensinamento de- } \\
& \text { pende ao mesmo tempo dos que aprendem e } \\
& \text { dos que ensinam. Antes de denunciar a inca- } \\
& \text { pacidade da maioria dos estudantes, deve-se }
\end{aligned}
$$

Movimento, Porto Alegre, v.12, n. 02, p. 199-221, maio/agosto de 2006. 
perguntar se existe, por parte dos professores, empenho em despertar o interesse dos alunos, e estimulá-los ao esforço e à autovalorização. (KOURGANOFF, 1990, p.20).

$\mathrm{Na}$ opinião dos docentes o curso deveria ser estruturado da seguinte forma: aumento da vivência da profissão, através de estágio e observação(três docentes); aumento de carga horária para disciplinas voltadas para formação de professores de ensino fundamental e médio (dois docentes) e estudo de caso (dois depoimentos). Dois entrevistados acreditam que devem ser incluídas no currículo disciplinas das áreas mãe como filosofia, sociologia, psicologia, pedagogia, antropologia, etiologia, biologia. E um docente acredita que todas as disciplinas deveriam ser interligadas. Outros dois não têm idéia de como o curso deveria ser estruturado.

A visão geral apresentada pelos docentes sobre a graduação em Educação Física é de que reformas precisam ocorrer para melhorar problemas estruturais do currículo. Dessa forma Bok (1988) alerta que é preciso dar prioridade a melhoria do ensino antes de incluir novos cursos, e para melhorar o ensino, há a necessidade da cooperação efetiva do corpo docente. E ainda argumenta que muitos resistirão a reformas, se estiverem piamente convencidos de que elas contribuirão para o avanço intelectual do aluno.

Então não é somente discutir quais disciplinas deveriam compor ou não a grade curricular de um curso de formação profissional. Mais do que isso, optar por conteúdos e disciplinas específicas que contribuam para a formação do profissional para atuar na licenciatura ou no bacharelado. É justamente isso que as Resoluções CNE/CP 01 e 02/2002 e 07/2004 defendem e que agora as Universidades que oferecem cursos de formação em Educação Física terão que respeitar, a partir da modificação ou extinção dos cursos de formação generalista.

Percebe-se, também, a necessidade de um aumento da vivência da profissão, isso pode representar um grande avanço para a for-

Movimento, Porto Alegre, v.12, n. 02, p. 199-221, maio/agosto de 2006. 
mação profissional, mudando a ênfase dada a realização de habilidades motoras, para o objetivo de treinar os graduandos a perceberem os problemas, analisá-los cuidadosamente e tomarem as decisões necessárias, ou seja, pensar como um profissional de Educação Física e não como um mero executor de tarefas e habilidades motoras (TEIXEIRA, 1993) Dessa forma, os graduandos serão guiados para ver, analisar e dar opiniões sobre situações do dia a dia profissional.

\section{Considerações finais}

Através da análise dos depoimentos dos docentes foi possível considerar que os elementos que devem compor a ação profissional em Educação Física não estão claramente definidos e caracterizados pelos docentes. Mas nota-se uma valorização da pesquisa científica, dos conhecimentos oriundos das áreas mães e de habilidades motoras.

Falta, portanto, aos docentes sentir-se responsável por sua contribuição ao progresso dos estudantes e ao tipo de profissional que se pretende formar, ou seja, falta a eles a certeza de que tipo de profissional se pretende colocar no mercado de trabalho. Por outro lado, essa falta de clareza também é motivada pelos conteúdos e disciplinas dos currículos generalistas de formação profissional.

Esta situação demonstra que ainda não possuem clareza do perfil profissional que pretendem formar, com isso, são formados graduandos (a) incapazes de atender os anseios da sociedade, (b) de pensar sobre os problemas característicos da profissão, (c) repetidores de sequiências pedagógicas e de métodos de ensino. Ou seja, forma-se profissionais acríticos, incapazes de propor novas sugestões a situações que ocorrem ou que possa ocorrer no mercado de trabalho.

Sendo assim, recomenda-se uma maior reflexão dos docentes sobre (a) os procedimentos e estratégias de ensino que são utiliza-

Movimento, Porto Alegre, v.12, n. 02, p. 199-221, maio/agosto de 2006. 
das, para verificar as necessidades dos graduandos e principalmente da sociedade, (b) cooperação efetiva do corpo docente para contribuir no avanço intelectual do aluno, deixando de lado, portanto, valores acadêmicos de preferência particulares de cada docente.

Como forma de ampliar nossos conhecimentos sugere-se a realização de outros estudos, nos quais possam abranger docentes de outras instituições de ensino para que haja maior representatividade dos docentes.

\footnotetext{
Knowledge of Professional Action in Physical Education: the Point of View of Cefd-Uel's Professors.

Abstract: It's undeniable that preparation courses are important and responsible for the exits close in job market. In this meaning, it's necessary to inquire some professors what they think about certain points related to the basic knowledge to act professionally in Physical Education. Therefore, this study has as objective to check the point of view of the professors of professional preparations in Physical Education at CEFD-UEL about: a) which elements should compose the Physical Education's professional act; b) how this elements are characterized. For this, 13 CEFD-UEL's professors have been interviewed; it's been used the analysis of contain as methodological procedure, with the proposal of the following categories previously established: the vision concerning the work market; acting according to work market; knowledge abilities and attitudes that will be developed during the graduation, which are important for professional intervention; evaluation system; point of view about Physical Education graduation. Although the studied group expresses some important concerns related to the valuation of knowledge that came from main disciplines, motive abilities and scientific research, it could be considered that manifested opinions in this study didn't allow us to define clearly neither characterize the elements that should compose the professional act in Physical Education.

Keywords: Professional Training. Teaching. Knowledge. Physical Education.
} 
El contenido de la intervención profesional en educación física: el punto de vista de los docentes de uno curso de formación profesional Resumen: El objetivo de ese estudio fue verificar el punto de vista de los docentes de uno curso de formación profesional sobre: (a) ¿ Como se catacteriza la intervención professional en Educación Física?; (b) ¿ Que elementos devem compone-los? (c) i y como esos elementos devem ser articulados por los professionais de Educación Física? Para eso, utilizamos la abordagem qualitativa y a partir de los dados obtenidos en la entrevista semi-estructurada, empleamos la análisis de contenido con las categorías préestablecidas á priori sobre (a) mercado de trabajo, (b) conocimientos, habilidades, actitudes a ser desarrolladas durante la graduación (c) sistema de avaliación, (d) visión de la graduación en Educación Física. Se pudo considerar que, a pesar del grupo estudiado expresar algunas preocupaciones importantes con relación à valoración de los conocimientos venidos de las asignaturas-madre, habilidades motoras y de investigación científica, los puntos de vista manifestados en este estudio en no permitieron definir claramente, ni caracterizar los elementos que deben componer la acción profesional en Educación Física.

Palabras-clave: Capacitación Profesional. Enseñanza. Conocimiento. Educación física.

\section{REFERÊNCIAS}

BARDIN, Laurence. Análise de conteúdo. Lisboa: Edições 70, 1979.

BETTI, Mauro. Por uma teoria prática. Revista Motus Corporis, Rio de Janeiro, v.3, n.2, p.73-127, 1996

BOK, Derik. Ensino superior. Rio de Janeiro: Forense Universitária, 1988.

BRASIL. Conselho Federal de Educação. Resolução CFE no. 03. Documenta, $n$. 315, p. 183-185, 1987

BRASIL. Ministério da Educação e Cultura. Conselho Nacional de Educação. Resolução CNE/CP 1/2002. Diário Oficial [da] República Federativa do Brasil, Brasília, DF, 9 abr. 2002. Seção 1, p. 31.

Movimento, Porto Alegre, v.12, n. 02, p. 199-221, maio/agosto de 2006. 
BRASIL. Ministério da Educação e Cultura. Conselho Nacional de Educação. Resolução CNE/CP 2/2002. Diário Oficial [da] República Federativa do Brasil, Brasília, DF, 4 mar. 2002. Seção 1, p. 9.

BRASIL. Ministério da Educação e Cultura. Conselho Nacional de Educação. Proposta alternativa ao parecer 138. Disponível em <www.mec.gov.br/cne/pdf/ fisica.pdf>. Acesso em: 22 mar. 2005.

FREIDSON, Eliot. Renascimento do profissionalismo: teoria, profecia e política. São Paulo: EDUSP, 1998.

GHILARDI, Reginaldo. Formação profissional em educação física: a relação teoria e prática. Revista Motriz, v.4, n.1, p.1-11, 1998.

GUARNIERI, Maria Regina. Aprendendo a ensinar: o caminho nada suave da docência. Campinas: Editores Associados, 2000.

KOURGANOFF, Wladimir. A face oculta da universidade. São Paulo: Ed. da UNESP, 1990

LAVILLE, Christian; DIONNE, Jean. A construção do saber: manual de metodologia da pesquisa em ciências humanas. Porto Alegre: Editora Artes; Editora UFMG, 1999.

NASCIMENTO, Glauce Yara. Como os profissionais de educação física avaliam as conseqüências de sua intervenção profissional a partir da perspectiva do erro. 2004. 98 f. Trabalho de conclusão de curso. Educação Física. Universidade Estadual de Londrina. Londrina, 2004.

REIS, Marize C. C. R. A identidade acadêmico-científica da Educação Física: uma investigação Campinas, 2002. $301 \mathrm{f}$. Tese (Doutorado). Faculdade de Educação Física, Universidade Estadual de Campinas. Campinas, 2002.

RICHARDSON, R. J. Pesquisa Social: métodos e técnicas. São Paulo: Atlas, 1999.

SCHEIN, Edgar H.; KOMMERS, Diane W. What is profession? In: SCHEIN, Edgar H. Professional Education: some new directions. New York: McGrawHill, 1972. p.7-14.

SCHÖN, D. A. Educando o profissional reflexivo: o novo design para o ensino e a aprendizagem. Tradução Roberto Cataldo Costa. Porto Alegre: Artes Médicas Sul, 2000.

SORIANO, Jeane B. A constituição da intervenção profissional em Educação Física: interações entre o conhecimento "formalizado" e a noção de competência. 2003. Tese (Doutorado). Faculdade de Educação Física, Universidade Estadual de Campinas. Campinas, 2003.

TANI, Go. Cinesilogia, educação física e esporte: ordem emanante do caos na estrutura acadêmica. Revista Motus Corporis, Rio de Janeiro, v.3, n.2, p.9-50, 1996.

Movimento, Porto Alegre, v.12, n. 02, p. 199-221, maio/agosto de 2006. 
TANI, Go. Vivências práticas no curso de graduação em Educação Física: necessidade, luxo ou perda de tempo? Caderno de documentos da Universidade de São Paulo, n.2, 1996.

TEIXEIRA, L. A. Estudo da motricidade humana como fonte de ordem para um tema científico, uma profissão, e um componente do currículo escolar. Revista Paulista de Educação Física, São Paulo, v. 7, n.8, p. 1993.

TRIVINÕS, Augusto N.S. Introdução à pesquisa em ciências sociais: a pesquisa qualitativa em educação. São Paulo: Atlas, 1987.

TRYLINSKI, Maria Helena C. V. O questionário na pesquisa psico-social. [s.I, S. n., 1974]. Mimeo.

VERENGUER, R. C. G. Preparação profissional em educação física: das leis à implementação dos currículos. 1996. 95 f. Dissertação (Mestrado) - Curso de Educação Física, Departamento de Faculdade de Educação Física, Universidade Estadual de Campinas, Campinas, 1996.

VERENGUER, Rita de Cássia G. Mercado de trabalho em educação física: significado da intervenção profissional à luz das relações de trabalho e da construção da carreira. Campinas, 2003. 170 f. Tese (Doutorado). Faculdade de Educação Física, Universidade Estadual de Campinas. Campinas. 